\title{
Serum Adipokines as Predictors for the Outcome of Prostate Biopsies at Early Stage Prostate Cancer Diagnosis
}

This article was published in the following Dove Press journal: Cancer Management and Research

\author{
Ardalan E Ahmad' \\ Aza Mohammed ${ }^{2}$ \\ Bimal Bhindi $\mathbb{D}^{1,3}$ \\ Patrick O Richard ${ }^{4}$ \\ Kamel Fadaak ${ }^{5}$ \\ Ricardo Leão $\mathbb{D}^{6}$ \\ Antonio Finelli ${ }^{1}$ \\ Neil E Fleshner' \\ Girish S Kulkarni' \\ 'Division of Urology, Department of \\ Surgery, University Health Network, \\ Princess Margaret Cancer Centre, \\ University of Toronto, Toronto, Ontario, \\ Canada; ${ }^{2}$ Department of Urology, Luton \\ and Dunstable University Hospital, Luton, \\ UK; ${ }^{3}$ Southern Alberta Institute of \\ Urology, Calgary, Alberta, Canada; \\ ${ }^{4}$ Division of Urology, Department of \\ Surgery, Centre Hospitalier Universitaire \\ de Sherbrooke, Centre de Recherche du \\ CHUS, Université de Sherbrooke, \\ Sherbrooke, Quebec, Canada; \\ ${ }^{5}$ Department of Urology, King Fahd \\ Hospital of the University, College of \\ Medicine, Imam Abdulrahman Bin Faisal \\ University, Dammam, Saudi Arabia; ${ }^{6} \mathrm{CUF}$ \\ Department of Urology, Hospital De \\ Braga, Faculty of Medicine, University of \\ Coimbra, Portugal
}

Correspondence: Girish S Kulkarni Division of Urology, Department of Surgery, University Health Network, Princess Margaret Cancer Centre, University of Toronto, 610 University Ave, 3-130, Toronto, ON M5G 2M9, Canada

$\mathrm{Tel}+$ I 4169462246

Fax + | 4169466590

Email girish.kulkarni@uhn.ca
Purpose: Elevated adipokines in patients with obesity and metabolic syndrome have been linked to increased risk of prostate cancer (PCa). The association between select serum adipokines and the outcome of prostate biopsies alone and in combination with clinical parameters at different early stages of PCa was investigated.

Patients and methods: Clinical data and serum adipokines were retrieved from three retrospective cohorts representing men at different points in PCa detection: 1. Subjects with no prior biopsies $(n=1061)$, 2. subjects with a prior negative biopsy (REDUCE trial, control arm) ( $n=1209), 3$. subjects with low-risk PCa on active surveillance (AS) ( $n=154)$. Adipokines were chosen based on an unpublished pilot study and included: Resistin, Tumor Necrosis Factor- $\alpha$, Interleukin-6, Monocyte Chemoattractant Protein-1, Hepatocyte Growth Factor, and Nerve Growth Factor. The primary outcome was the absence of PCa on biopsy and the secondary outcome was diagnosis of low-risk PCa fitting the criteria for continuing AS. Logistic regression analysis was used to assess the association of adipokines and negative and/or low-risk PCa at prostate biopsy.

Results: In men with no prior prostate biopsy or with prior negative biopsy, adipokines were not predictors of prostate biopsy outcomes on multivariable regression analysis controlling for known clinical variables. In the AS cohort, MCP-1 and Resistin were significant predictors of biopsy outcome on multivariable analysis (OR $0.20,95 \%$ CI: $0.05-0.85, \mathrm{p}=$ $0.03 \&$ OR $0.30,95 \%$ CI: $0.10-0.86, p=0.03$ ).

Conclusion: Our findings do not support a strong role for adipokines for predicting the outcome of prostate biopsies at any early stage in PCa diagnosis.

Keywords: adipokines, biopsy outcomes, prostate biopsy, early prostate cancer

\section{Plain Language Summary}

Adipokines, cytokines produced by adipocytes, have been linked to increased prostate cancer (PCa) risk. We investigate the association between select serum adipokines and outcome of prostate biopsies at different early stages of PCa. In biopsy naïve men or men with prior negative biopsy, adipokines were not predictors of prostate biopsy outcomes. In active surveillance cohort, Monocyte Chemoattractant Protein-1 and Resistin were significant predictors of biopsy outcome; however, the association was not clinically significant. Our findings do not support a strong role for adipokines for predicting the outcome of prostate biopsies at any early stage in PCa diagnosis.

\section{Introduction}

Prostate cancer (PCa) is the most common non-cutaneous malignant tumour diagnosed in men and the second leading cause of cancer death. ${ }^{1}$ The increasing 
prevalence of PSA screening worldwide was paralleled by an increase in the detection of low-risk PCa raising the issues of over-detection and over-treatment. ${ }^{2}$ As a result, patients with low-risk PCa are often managed with active surveillance (AS) which requires frequent biopsies to assess possible disease progression. ${ }^{3}$

With PSA screening and rapid adoption of AS, the rate of prostate biopsy has increased. ${ }^{2}$ Prostate biopsy is the gold standard in the diagnosis of PCa and in the follow-up of patients on AS. However, transrectal ultrasound (TRUS) prostate biopsy is associated with wellestablished morbidity and even mortality. ${ }^{4}$ Accordingly, there has been an increasing demand for clinical tools, biomarkers, and nomograms to allow clinicians to predict the outcomes of prostate biopsies with some degree of certainty, hence reduce the need for unnecessary biopsies.

One group of biomarkers that have garnered attention for PCa detection are the adipokines. Adipokines are cytokines or hormones derived from adipocytes and are linked to obesity, a state of chronic inflammation, and increased risk of a variety of malignancies, including $\mathrm{PCa}^{5}$ The association between obesity, metabolic syndrome, and the increased risk of PCa has been extensively studied in the literature in recent years. ${ }^{6-11}$ This link can be explained through the alteration in levels of testosterone and insulinlike growth factors (IGF) in obese patients as well as secretion of different adipocytes-derived substances (adipokines) that can alter the biological behaviour of $\mathrm{PCa}$ cell. ${ }^{12}$ Several of these adipokines have been identified and studied for their role in the pathogenesis of $\mathrm{PCa} .{ }^{13}$

There exists limited data on the role of adipokines as predictors of prostate biopsy outcomes. We hypothesized that serum adipokines could be used to complement clinical variables and thus enhance the prediction of prostate biopsy outcomes. This, in return, could defer or reduce biopsy rates in select cohorts of patients.

\section{Materials and Methods}

\section{Study Overview}

This study received approval from the research ethics board at the University Health Network (UHN) prior to commencement. We aimed to identify representative cohorts that describe a patient's pathway through $\mathrm{PCa}$ diagnosis and early detection and then ascertain the utility of adipokine as serum markers at each phase at predicting biopsy outcomes. Figure 1 depicts a hypothetical pathway and the rationale for the cohorts utilized. Three important phases in PCa early detection where biopsy morbidity can occur are illustrated: 1) first (initial) biopsy, 2) repeat biopsies after prior negative biopsy, and 3) biopsies while on AS. The impact of known clinical parameters and adipokine biomarker values on prostate biopsy outcome was assessed at each setting.

\section{Patient Cohorts}

Three large retrospective cohorts with both clinical data and stored sera (to enable adipokine measurement at the time of biopsy) were assembled to represent each of the three clinical scenarios in urology practice. 1) De novo (initial) biopsy patients were identified using UHN institutional Genitourinary (GU) Biobank. Starting in September 2008, we have been prospectively enrolling men undergoing prostate biopsy by recording clinical characteristics and storing serum samples at the time of

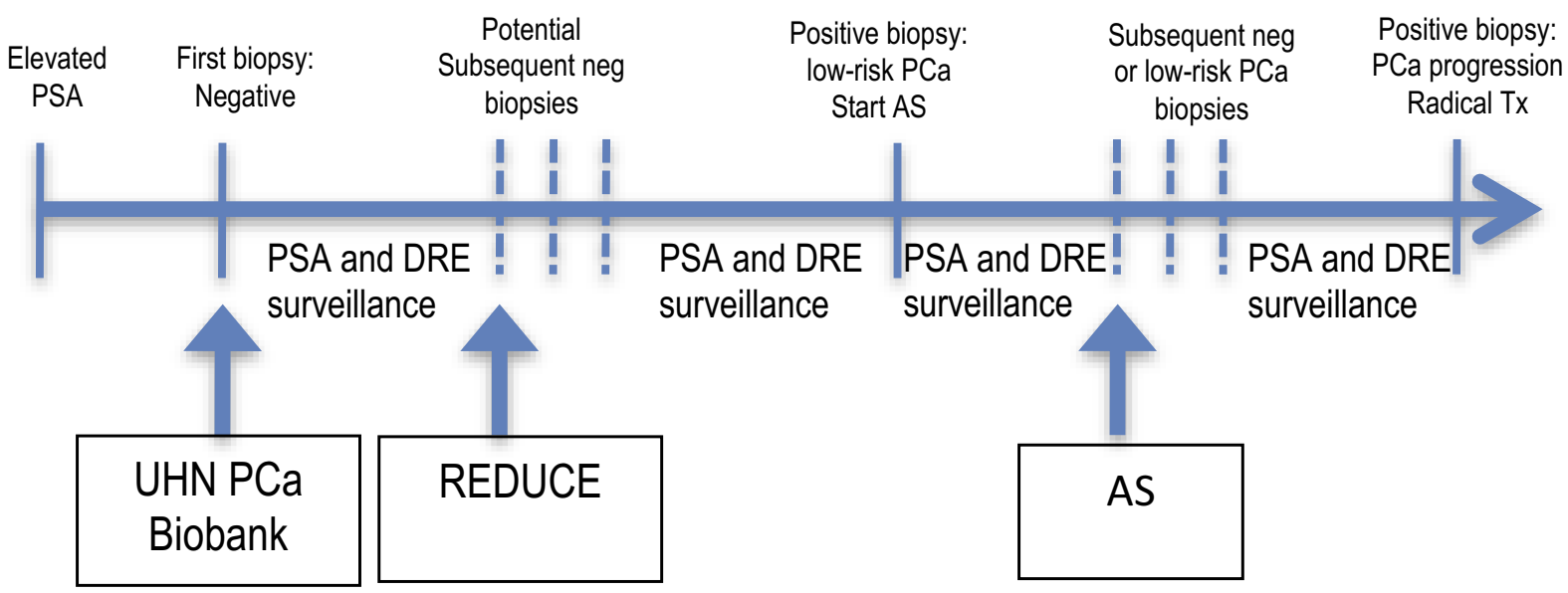

Figure I Diagram representing a common trajectory in men who are candidates for prostate biopsy based on PSA or prior history of prostate cancer. Abbreviations: PSA, prostate-specific antigen, PCa, prostate cancer, REDUCE, Reduction by Dutasteride of Prostate Cancer Events, DRE, digital rectal exam, AS, active surveillance. 
biopsy. ${ }^{7,14}$ Biopsies were performed by high volume radiologists and read by dedicated GU pathologists. 2) Patients accrued in the placebo arm of the Reduction by Dutasteride of Prostate Cancer Events (REDUCE) trial served as the cohort representing repeat biopsy cohort after an initial negative biopsy. ${ }^{15}$ In this multiinstitutional-randomized controlled trial of 6729 men comparing Dutasteride to placebo for the chemoprevention of $\mathrm{PCa}$, only patients with a prior negative prostate biopsy were enrolled. These patients underwent repeat biopsy at follow-up years 2 and 4 . We used individual patient clinical variables and serum samples at the year-2 biopsy in 1300 randomly selected placebo patients.

3) The final cohort consisted of men from our local Active Surveillance database between 1/2006 and 3/2012. A total of 154 AS patients were available for assessment who had clinical and serum data housed at UHN. Once confirmed as low-risk, low volume PCa and deemed eligible for AS (based on initial diagnostic biopsy), these patients undergo confirmatory biopsy at the 6-12-month mark and then every 1-3 years thereafter. Sera and clinical data prior to the 6-12 months biopsy were interrogated.

\section{Outcomes}

The primary outcome measure was the absence of $\mathrm{PCa}$ (i.e., a negative biopsy). As previously published, the secondary outcome of interest was low-risk PCa, defined as Gleason Score $\leq 6$, number of positive cores $\leq 3$, and $\leq 50 \%$ involvement in any positive core by $\mathrm{PCa} .{ }^{14}$

\section{Clinical Covariates}

This study used patients' clinical data and serum samples to determine important predictors of absent $\mathrm{PCa}$ or indolent PCa. For all patients, clinical data and blood samples were collected prior to each biopsy. The clinical variables included age, PSA, a family history of $\mathrm{PCa}$, digital rectal examination (DRE), prostate volume, and body mass index (BMI). In the AS cohort, we also adjusted for Dutasteride use as this medication has been demonstrated to alter negative biopsy rates in AS patients. ${ }^{16}$

\section{Adipokine Biomarkers}

Based on unpublished pilot data from UHN, 6 different adipokines were included for assessment: Tumor Necrosis Factor- $\alpha$ (TNF- $\alpha$ ), Interleukin-6 (IL-6), hepatocyte growth factor (HGF), monocyte chemoattractant protein (MCP-1), Nerve Growth Factor (NGF) and Resistin. Adipokine assays were carried out in magnetic plates and according to Millipore Human Magnetic Bead Panel 1 and Panel 2 Assay Protocol (Millipore Sigma, Merck KGaA, Darmstadt, Germany). Specimens were diluted 1:400 in assay buffer for panel 1 and run as neat for panel 2 . Twenty-five $\mu \mathrm{L}$ of the specimen was incubated with $25 \mu \mathrm{L}$ of magnetic beads and $25 \mu \mathrm{L}$ assay buffer for 18 hrs at $4^{\circ} \mathrm{C}$. The assay mixture was washed $3 \times$ with $200 \mu \mathrm{L}$ of wash buffer and incubated with $50 \mu \mathrm{L}$ of detection antibody for $1 \mathrm{hr}$ at room temperature. Fifty $\mu \mathrm{L}$ streptavidin-phycoerythrin was then added to the assay mixture and incubated at room temperature for another 30 minutes. The assays were washed again $3 \times$, and magnetic beads were resuspended in $100 \mu \mathrm{L}$ of sheath fluid. The Luminex 100 Reader was utilized to read the assay and data were analyzed using Bio-plex Manager 6.0.

\section{Statistical Methods}

Individual risk factors and adipokines were compared with parametric ( $t$-test) and non-parametric tests (Wilcoxon Rank Sum) for continuous variables as well as Chi-squared test for categorical variables. Univariable and multivariable logistic regression model were used to identify statistically significant predictors of negative biopsy and/or low-risk PCa. A purposeful selection strategy, which outperforms other methods in retaining confounders, was used to build the multivariable models. ${ }^{17}$ Internal validation of the biomarker signature was performed using leave-one-out cross-validation, least absolute shrinkage and selection operator and/or k-fold validation. Model predictive accuracy was analyzed using sensitivity, specificity, ROC and area under the curve (AUC) analyses. ${ }^{18,19}$ P-values $<0.05$ were considered significant. The analyses were performed in R environment (www.R-project.org, version 3.3.1).

\section{Ethical Approval and Informed Consent}

This study received approval from the research ethics board at the University Health Network (UHN) prior to commencement. The need for written informed consent was waived by the Ethics Committee because of the retrospective nature of this study. This study was conducted following the Declaration of Helsinki.

\section{Results}

Clinical data and serum samples for a total of 2404 patients were available as follows: Cohort 1: UHN GU Biobank patients presenting for first prostate biopsy $(\mathrm{n}=1061)$, Cohort 2: REDUCE trial participants (placebo 
arm) all of whom have had a negative prior prostate biopsy $(n=1209)$ and Cohort 3: AS cohort $(n=154)$. Baseline clinical and demographic characteristics and adipokines levels for each cohort are demonstrated in Table 1 . In the AS cohort, 14\% $(n=22)$ of patients were using 5-alpha- reductase inhibitors compared to $86 \%(n=132)$ who were not on 5-alpha-reductase inhibitors.

In the UHN GU Biobank cohort (biopsy naïve cohort), 506 patients were diagnosed with PCa at initial biopsy (192 Gleason 6, 313 Gleason 7 or higher, 1 undetermined grade)

Table I Clinical Characteristics and Serum Adipokine Values in the Three Cohorts

\begin{tabular}{|c|c|c|c|}
\hline Variable & GU Biobank Cohort & REDUCE Cohort & AS Cohort \\
\hline Number of patients & 1061 & 1209 & 154 \\
\hline \multicolumn{4}{|c|}{ Patient's Characteristics } \\
\hline $\begin{array}{l}\text { Age, }(\mathbf{y r}) \\
\quad \text { Median (IQR) }\end{array}$ & $61.8(55.6-67.3)$ & $65.0(60.0-69.0)$ & $65.4(60.0-69.6)$ \\
\hline $\begin{array}{l}\text { PSA (ng/mL) } \\
\text { Median (range) }\end{array}$ & $5.3(0.0-165.2)$ & $5.9(0.6-122.4)$ & $4.7(0.4-17.6)$ \\
\hline $\begin{array}{l}\text { Digital rectal exam } \\
\text { Normal (\%) } \\
\text { Abnormal (\%) }\end{array}$ & $\begin{array}{l}763(71.9) \\
295(27.8)\end{array}$ & $\begin{array}{l}\text { II } 68(96.6) \\
4 I(3.4)\end{array}$ & $\begin{array}{l}\text { I43(93) } \\
\text { II (7) }\end{array}$ \\
\hline $\begin{array}{l}\text { Prostate volume (m } \\
\text { Median (range) }\end{array}$ & $40.0(5.0-204.0)$ & $44.3(7.7-|7| .5)$ & $45.0(11.0-125.0)$ \\
\hline $\begin{array}{l}\text { BMI } \\
\quad \text { Median (IQR) }\end{array}$ & $26.6(24.4-29.4)$ & $27.0(24.7-29.6)$ & $27.0(25.05-28.55)$ \\
\hline $\begin{array}{l}\text { Family history (\%) } \\
\text { Positive } \\
\text { Negative }\end{array}$ & $\begin{array}{l}19.0 \\
76.0\end{array}$ & $\begin{array}{l}11.8 \\
88.2\end{array}$ & $\begin{array}{l}25 \\
75\end{array}$ \\
\hline Adipokines & & & \\
\hline $\begin{array}{l}\text { IL-6 (pg/mL) } \\
\text { Median (IQR) } \\
\text { Range }\end{array}$ & $\begin{array}{l}2.5(1.3-4.7) \\
0.0-192.4\end{array}$ & $\begin{array}{l}2.9(1.5-5.3) \\
0.0-1157.2\end{array}$ & $\begin{array}{l}\text { I. }(1.0-3.2) \\
0.0-64.1\end{array}$ \\
\hline $\begin{array}{l}\text { TNF-alpha }(\mathrm{pg} / \mathrm{mL}) \\
\text { Median (IQR) } \\
\text { Range }\end{array}$ & $\begin{array}{l}4.9(3.6-6.7) \\
0.1-64.3\end{array}$ & $\begin{array}{l}4.1(2.8-5.5) \\
0.0-258.6\end{array}$ & $\begin{array}{l}4.5(3.3-5.7) \\
0.0-21.9\end{array}$ \\
\hline $\begin{array}{l}\text { HGF (ng/mL) } \\
\text { Median (IQR) } \\
\text { Range }\end{array}$ & $\begin{array}{l}688.9(430.2-1003.5) \\
1.2-8940.8\end{array}$ & $\begin{array}{l}501.9(306.4-770.8) \\
0.0-16,717.4\end{array}$ & $\begin{array}{l}411.6(250.3-718.8) \\
0.2-3322.4\end{array}$ \\
\hline $\begin{array}{l}\text { MCP-I (pg/mL) } \\
\text { Median (IQR) } \\
\text { Range }\end{array}$ & $\begin{array}{l}312.9(229.5-406.2) \\
15.3-1488.8\end{array}$ & $\begin{array}{l}266.3(186.8-377.0) \\
0.0-1999.5\end{array}$ & $\begin{array}{l}246.9(\mid 57.7-328.6) \\
1.8-988.6\end{array}$ \\
\hline $\begin{array}{l}\text { NGF }(\mathrm{pg} / \mathrm{mL}) \\
\text { Median (IQR) } \\
\text { Range }\end{array}$ & $\begin{array}{l}4.4(2.2-7.6) \\
0.1-461.2\end{array}$ & $\begin{array}{l}4.4(2.9-6.4) \\
0.0-3020.8\end{array}$ & $\begin{array}{l}2.9(1.8-4.3) \\
0.0-83.5\end{array}$ \\
\hline $\begin{array}{l}\text { Resistin (ng/mL) } \\
\text { Median (IQR) } \\
\text { Range }\end{array}$ & $\begin{array}{l}12,875.0(9502.0-17,288.2) \\
1.3-75,895.2\end{array}$ & $\begin{array}{l}21,814.3(15,902.9-30,389.6) \\
0.0-332,705.6\end{array}$ & $\begin{array}{l}15,706.4(10,477.5-22,189.2) \\
2729.8-6 \mid, 050.9\end{array}$ \\
\hline
\end{tabular}

Abbreviations: PSA, prostate-specific antigen; BMI, body mass index; IL, interleukin; TNF, tumor necrosis factor; HGF, hepatocyte growth factor; MCP, monocyte chemoattractant protein; NGF, nerve growth factor; IQR, interquartile range; GU, genitourinary; AS, active surveillance. 
while 555 had negative biopsies. On univariable analysis, only IL-6 was associated with no and/or low-risk PCa (OR 1.17, 95\% CI: $1.05-1.30, \mathrm{p}=0.006)$. In the REDUCE trial control arm cohort (prior negative biopsy), a total of 213 patients were diagnosed with $\mathrm{PCa}$ at year 2 biopsy (133 Gleason 6,80 Gleason 7 or higher) while 996 patients had a negative biopsy. On univariable analysis, none of the adipokines were found to be associated with no and/or low-risk PCa. Finally, in the AS cohort, 123 patients remained with the diagnosis of low-risk-PCa on the confirmatory biopsy compared to 31 patients who were upgraded. On univariable analysis, there was no statistically significant association between the level of individual serum adipokines and the presence of clinically significant $\mathrm{PCa}$.

On multivariable analysis, for the UHN GU biobank cohort, IL-6 lost its statistical significance when the model was adjusted for other clinical variables $(p=0.051$; Table 2). In the REDUCE trial cohort, none of the adipokines were found to be associated with the outcome of prostate biopsies on multivariable analysis (Table 3). For the AS cohort, on multivariable analysis, two adipokines MCP-1 (OR 1.00, 95\% CI: 0.99-1.00, $\mathrm{p}=0.03$ ) and Resistin (OR 1.00, 95\% CI: 1.00-1.00, $\mathrm{p}=0.008$ ) were found to be statistically significant predictors for the outcome of prostate biopsy (selected by leave-one-out cross

Table 2 Multivariable Analysis - Adipokines as Predictors of Low-Risk/No Risk Prostate Cancer in the UHN GU Biobank Cohort (Biopsy Naïve) Adjusted for Clinical Variables

\begin{tabular}{|l|l|l|l|l|l|}
\hline Variable & $\begin{array}{l}\text { Continuous/ } \\
\text { Reference } \\
\text { Group }\end{array}$ & OR & \multicolumn{2}{|l|}{$\begin{array}{l}\text { 95\% Cl of } \\
\text { OR }\end{array}$} & P value \\
\hline Age & Continuous & 1.03 & 1.01 & 1.04 & 0.007 \\
\hline PSA (log) & Continuous & 3.06 & 2.35 & 3.99 & $<0.001$ \\
\hline DRE* (N vs Y) & Normal & 3.51 & 2.55 & 4.84 & $<0.001$ \\
\hline $\begin{array}{l}\text { Family history } \\
\text { (N vs Y) }\end{array}$ & Negative & 1.50 & 1.05 & 2.16 & 0.03 \\
\hline $\begin{array}{l}\text { Ethnicity } \\
\text { African vs } \\
\text { Europeans } \\
\text { Other (2-5) } \\
\text { vs Europeans }\end{array}$ & Europeans & 1.15 & 0.61 & 2.15 & 0.7 \\
\hline \begin{tabular}{l} 
IL-6 \\
\hline
\end{tabular} & Continuous & 1.13 & 1.00 & 1.28 & 0.05 \\
\hline
\end{tabular}

Notes: AUC: 0.756. Out-of-sample AUC: 0.75I. MSE: 0.183, AIC: 1094.0. *Positive DRE. ORs of continuous variables were calculated using one-unit increasing. Abbreviations: PSA, prostate-specific antigen; DRE, digital rectal exam; IL, interleukin; AIC, Akaike information criterion; AUC, area under the curve; OR, odd's ratio; $\mathrm{N}$, no; $\mathrm{Y}$, yes.
Table 3 Multivariable Analysis - Adipokines (IL-6, NGF) as Predictors of Low -Risk/No Risk Prostate Cancer in the REDUCE Trial Cohort Adjusted for Clinical Variables

\begin{tabular}{|c|c|c|c|c|c|}
\hline Variable & $\begin{array}{l}\text { Continuous/ } \\
\text { Reference } \\
\text { Group }\end{array}$ & OR & \multicolumn{2}{|c|}{$\begin{array}{l}95 \% \mathrm{Cl} \text { of } \\
\text { OR }\end{array}$} & $P$ Value \\
\hline Age at 2yr Biopsy & Continuous & 0.94 & 0.90 & 0.98 & 0.008 \\
\hline DRE & & & & & 0.10 \\
\hline $\begin{array}{l}\text { Abnormal, no } \\
\text { change }\end{array}$ & Normal & 2.92 & 0.35 & 24.25 & 0.30 \\
\hline $\begin{array}{l}\text { Abnormal, } \\
\text { changed }\end{array}$ & Normal & 0.26 & 0.05 & 1.26 & 0.01 \\
\hline Log (Present PSA) & Continuous & 0.52 & 0.26 & 1.02 & 0.06 \\
\hline $\begin{array}{l}\text { Log (PSA) } \\
\text { Change }\end{array}$ & Continuous & 0.65 & 0.30 & 1.42 & 0.30 \\
\hline $\begin{array}{l}\text { Prior History of } \\
\text { HGPIN: Yes }\end{array}$ & No & 0.30 & 0.16 & 0.543 & $<0.001$ \\
\hline $\begin{array}{l}\text { Number of Cores } \\
\text { at Baseline Biopsy }\end{array}$ & Continuous & 1.16 & 1.04 & 1.30 & 0.009 \\
\hline Prostate Volume & Continuous & 1.03 & 1.01 & 1.050 & $0<0.001$ \\
\hline IL-6 & Continuous & 1.02 & 0.99 & 1.07 & 0.20 \\
\hline NGF & Continuous & 1.00 & 0.98 & 1.03 & 0.80 \\
\hline
\end{tabular}

Notes: AUC: 0.780. Out-of-sample AUC: 0.778. MSE: 0.057, AIC: 5I6.8. ORs of continuous variables were calculated using one unit increasing. Clinical variables: age, DRE, Log PSA, Log PSA change, history of HGPIN, number of biopsy cores and prostate volume.

Abbreviations: PSA, prostate-specific antigen; DRE, digital rectal exam; IL, interleukin; AIC, Akaike information criterion; AUC, area under the curve; OR, odd's ratio; HGPIN, high grade prostatic intraepithelial neoplasia; MSE, mean squared error.

validation for predicting low-risk or no prostate cancer) (Tables 4 and 5).

The odds ratio (OR) represents a risk ratio for a single unit increase in MCP-1 and Resistin which has limited clinical utility. Given the above, we categorized MCP-1 and Resistin into clinically meaningful quartiles and tertiles to determine their true effect in the AS cohort. On multivariable analysis, the highest MCP-1 quartile was significantly associated with no and/or low-risk PCa on prostate biopsy (OR $0.20,95 \%$ CI: $0.05-0.85, \mathrm{p}=0.03$ ). Similarly, for Resistin, the highest tertile was found to be significantly associated with no and/or low-risk PCa on prostate biopsy (OR $0.30,95 \%$ CI: $0.10-0.86, p=0.03$ ). We further categorized Resistin and MCP-1 into clinically meaningful quartiles and tertiles to determine its true effect, respectively. However, modeling Resistin as quartiles and MCP-1 as tertiles failed to show a significant association with the prediction of prostate biopsies result on the multivariable regression model. 
Table 4 Multivariable Analysis - Adipokine (MCP-I) as Predictor of Low-Risk/No Risk Prostate Cancer in the AS Cohort Adjusted for Clinical Variables

\begin{tabular}{|c|c|c|c|c|c|}
\hline Variable & $\begin{array}{l}\text { Continuous/ } \\
\text { Reference } \\
\text { Group }\end{array}$ & OR & \multicolumn{2}{|c|}{$\begin{array}{l}95 \% \mathrm{Cl} \text { of } \\
\text { OR }\end{array}$} & $P$ value \\
\hline Present PSA & Continuous & 0.78 & 0.67 & 0.92 & 0.003 \\
\hline $\begin{array}{l}\text { Number of } \\
\text { Positive Cores at } \\
\text { Baseline Biopsy }\end{array}$ & Continuous & 0.49 & 0.26 & 0.94 & 0.03 \\
\hline Prostate Volume & Continuous & 1.04 & 1.01 & 1.07 & 0.016 \\
\hline $\begin{array}{l}\text { Digital Rectal } \\
\text { Exam: Abnormal }\end{array}$ & Normal & 0.15 & 0.03 & 0.85 & 0.03 \\
\hline MCP-I & Continuous & 1.00 & 0.99 & 1.00 & 0.03 \\
\hline
\end{tabular}

Notes: AUC: 0.812 . Out-of-sample AUC: 0.779. MSE: 0.148, AIC: 124.6. ORs of continuous variables were calculated using one unit increasing. Clinical variables: DRE, PSA, number of biopsy cores and prostate volume.

Abbreviations: PSA, prostate-specific antigen; DRE, digital rectal exam; MCP, monocyte chemoattractant protein; AIC, Akaike information criterion; AUC, area under the curve; OR, odd's ratio; MSE, mean squared error.

Table 5 Multivariable Analysis - Adipokine (Resistin) as Predictor of Low-Risk/No Risk Prostate Cancer in the AS Cohort Adjusted for Clinical Variables

\begin{tabular}{|l|l|l|l|l|l|}
\hline Variable & $\begin{array}{l}\text { Continuous/ } \\
\text { Reference } \\
\text { Group }\end{array}$ & OR & \multicolumn{2}{|l|}{$\begin{array}{l}\text { 95\% Cl of } \\
\text { OR }\end{array}$} & P value \\
\hline $\begin{array}{l}\text { Present PSA } \\
\text { Number of Cores }\end{array}$ & $\begin{array}{l}\text { Continuous } \\
\text { Continuous }\end{array}$ & $\begin{array}{l}0.81 \\
1.33\end{array}$ & $\begin{array}{l}1.68 \\
\text { Taken on Baseline }\end{array}$ & 0.96 & 0.01 \\
$\begin{array}{l}\text { Biopsy } \\
\text { Number of }\end{array}$ & Continuous & 0.47 & 0.25 & 0.88 & 0.02 \\
$\begin{array}{l}\text { Positive Cores at } \\
\text { Baseline Biopsy } \\
\text { Prostate Volume } \\
\text { DRE: }\end{array}$ & Continuous & 1.02 & 1.00 & 1.05 & 0.08 \\
Abnormal & Normal & 0.10 & 0.02 & 0.59 & 0.01 \\
Resistin & Continuous & 1.00 & 1.00 & 1.00 & 0.008 \\
\hline
\end{tabular}

Notes: AUC: 0.816. Out-of-sample AUC: 0.766 . MSE: 0.182, AIC: 146.2. ORs of continuous variables were calculated using one unit increasing. Clinical variables: DRE, PSA, number of biopsy cores and prostate volume.

Abbreviations: PSA, prostate-specific antigen; DRE, digital rectal exam; AIC, Akaike information criterion; AUC, area under the curve; OR, odd's ratio; MSE, mean squared error.

\section{Discussion}

This is the first, large-scale study examining the role of adipokines in predicting the outcome of prostate biopsies. Three different retrospective cohorts with banked sera representing different points in the detection of $\mathrm{PCa}$ in urology practice were utilized. Despite the growing body of evidence that links obesity and metabolic syndrome to the increased risk of developing $\mathrm{PCa}$, and the association of some adipokines and $\mathrm{PCa}$ risk, the independent predictive value of adipokines beyond the clinical parameters in predicting the presence of $\mathrm{PCa}$ or the grade of the biopsy is not clearly defined.

Our results have demonstrated that in the UHN GU Biobank (biopsy naïve cohort) and the REDUCE trial cohorts (men with prior negative prostate biopsy) none of the adipokines examined achieved statistical significance in predicting the outcome of prostate biopsies on multivariable analysis. In the AS cohort, on the other hand, two of the adipokines (MCP-1 and Resistin) achieved statistical significance on multivariable regression analysis. However, given that the OR represented a single unit rise in the MCP-1 and Resistin levels with limited clinical utility, we categorized MCP-1 and Resistin to clinically meaningful quartiles and tertiles. On multivariable regression analysis, controlling for known clinical parameters, MCP-1 and Resistin in the highest quartile and tertile were found to be associated with higher risk $\mathrm{PCa}$, respectively. These findings will need further validation in a larger cohort of patients enrolled in a prospective active surveillance program.

Adipokines have been studied extensively in PCa. Price et al, demonstrated an increased rate of PCa cell migration, proliferation and invasiveness in vitro when exposed to high levels of IL-6, VEGF, plasminogen activator inhibitor 1 (PAI-1), and Leptin suggesting a role for these adipokines in the pathogenesis of $\mathrm{PCa} .{ }^{20}$ Sharma et al, also showed that higher levels of adipokines (MCP-1, IL-1, 2, 6 and 8 and TNF- $\alpha$ ) were significantly correlated with worse outcomes in patients with metastatic $\mathrm{PCa}$ on androgen deprivation therapy (ADT). ${ }^{21}$ In our cohorts, IL-6, MCP-1, and Resistin were found to be associated with the risk of PCa. IL-6 has been linked to increased risk of PCa in both clinical and in vitro studies. ${ }^{22,23}$ At a molecular level, however, Moore et al, failed to demonstrate any link between polymorphisms in the IL-6 gene and increased risk of PCa. ${ }^{24}$ Similarly, in a nested case-control study, Baillargeon et al, showed a lack of association between IL-6 levels and the prediction of $\mathrm{PCa}$ diagnosis or aggressiveness. ${ }^{5} \mathrm{MCP}-1$ induces proliferation and increases the invasiveness of PCa cells. Higher levels of MCP-1 expression were associated with advanced stages of $\mathrm{PCa} .{ }^{25}$ In addition, increased MCP-1 expression is associated with increased risk of bony metastasis in PCa and a MCP-1 gene knockdown was found to decrease tumour growth in the bone. ${ }^{26}$ Finally, Resistin is expressed in PCa cell lines and induces PCa cell proliferation. ${ }^{27}$ However, in a separate report, there were no changes in the serum levels of Resistin in patients on 
ADT, implying a poor clinical correlation with $\mathrm{PCa}$ treatment. ${ }^{28}$ Adipokines have been studied extensively in $\mathrm{PCa}$ but none has been shown to be a major clinical predictor of $\mathrm{PCa}$.

This study is not without limitations. First, the retrospective nature of the study poses inherent biases that accompany any retrospective analyses. For example, data on patients' comorbidities (diabetes) and/or current medication use (statins) were not available. Second, we excluded Adiponectin as a metabolic marker. Adiponectin has been studied in the literature as a marker for $\mathrm{PCa}$ diagnosis or aggressiveness. Nishimura et al, examined the association between Adiponectin and increased risk of $\mathrm{PCa}$ in two cohorts; one group of patients with $\mathrm{PCa}$ and a control group of normal subjects. The group concluded that Adiponectin was significantly associated with the risk of PCa when adjusted for age, body weight, and prostate volume. ${ }^{28,29}$ However, these results should be interpreted with caution in the setting of a small patient sample $(n=54)$. Contrary to the study by Nishimua et al, other studies have identified Adiponectin as an inhibitor of PCa growth. ${ }^{30-32}$ Considering the above discrepancies and the lack of a signal for Adiponectin in our pilot work, we elected not to include Adiponectin in our study. Third, the small number of AS patients $(n=154)$ may have precluded the discovery of a stronger association between adipokines and the risk of clinically significant PCa. Fourth, prostate magnetic resonance imaging (MRI) has proved to be an important adjunct tool in the diagnosis and management of $\mathrm{PCa}$; however, it was not routinely obtained during the study period. Therefore, we could not address its role and impact in this clinical conundrum. Fifth, in all three cohorts, based on median BMI (26.6-27.0) patients are classified as overweight. Nevertheless, adipokines may have a potential role as predictors of prostate biopsy outcomes in patients with higher BMI (obese and morbidly obese patients). Despite these limitations, our study presents the largest series of patients in whom adipokines have been measured prior to undergoing prostate biopsy. Short of a randomized trial (prospective) investigating a larger adipokines panel (including adiponectin), this study represents the most definitive evidence regarding the role of adipokines in predicting prostate biopsy outcomes. We did not specifically assess the potential economic and quality of life-related benefits associated with implementing adipokine measurement prior to prostate biopsy. However, pending the confirmation of the diagnostic utility of adipokines prior to prostate biopsy, these markers may potentially decrease the anxiety and the cost associated with prostate biopsy by effectively excluding men who are not at risk of harboring clinically significant prostate cancer.

\section{Conclusion}

Our study has failed to demonstrate a clinically strong association between select adipokines and the risk of PCa. In the cohorts analyzed, these markers could not be used as predictors for the outcome of prostate biopsies, although significantly elevated MCP-1 and Resistin (when categorized into clinically meaningful quartiles and tertiles, respectively) were associated with low-risk/no risk prostate cancer. Further studies to validate our results and to identify predictive markers of prostate biopsy outcome are required.

\section{Acknowledgments}

Funding source: Prostate cancer Canada Clinician Scientist Award CSA2012-45 and Canadian Urological Association Scholarship Fund Early Investigator Research Scholarship.

\section{Disclosure}

Dr Neil E Fleshner reports personal fees from Abbvie, Amgen, Astellas, Bayer, Ferring, Janssen, Sanofi, and Hydbridyne Health outside the submitted work. He additionally reports grants from Bayer, Ferring, Janssen, Sanofi, Bavarian Nordic, Medication, Nucleix, Progenics, and Spectracure outside the submitted work. Dr Girish S Kulkarni reports grants from Prostate Cancer Canada and Canadian Urological Association Scholarship Fund, during the conduct of the study. Janssen, Ferring, Roche, Merk and Theralase provided funding to support the urology oncology fellowship program at the University of Toronto outside the submitted work. The authors report no other conflicts of interest in this work.

\section{References}

1. Siegel RL, Miller KD, Jemal A. Cancer statistics, 2018. CA Cancer J Clin. 2018;68:7-30. doi:10.3322/caac.21442

2. Cooperberg MR, Lubeck DP, Meng MV, et al. The changing face of low-risk prostate cancer: trends in clinical presentation and primary management. J Clin Oncol. 2004;22:2141-2149. doi:10.1200/JCO.20 04.10 .062

3. Klotz L, Vesprini D, Sethukavalan P, et al. Long-term follow-up of a large active surveillance cohort of patients with prostate cancer. J Clin Oncol. 2015;33:272-277. doi:10.1200/JCO.2014.55.1192

4. Nam RK, Saskin R, Lee Y, et al. Increasing hospital admission rates for urological complications after transrectal ultrasound guided prostate biopsy. J Urol. 2013;189:S12-7; discussion S17-8. doi:10.1016/j. juro.2012.11.015

5. Hsing AW, Sakoda LC, Chua S Jr. Obesity, metabolic syndrome, and prostate cancer. Am J Clin Nutr. 2007;86:S843-S857. doi:10.1093/ ajen/86.3.843S 
6. Baillargeon J, Platz EA, Rose DP, et al. Obesity, adipokines, and prostate cancer in a prospective population-based study. Cancer Epidemiol Biomarkers Prev. 2006;15:1331-1335. doi:10.1158/10559965.EPI-06-0082

7. Bhindi B, Locke J, Alibhai SMH, et al. Dissecting the association between metabolic syndrome and prostate cancer risk: analysis of a large clinical cohort. Eur Urol. 2015;67:64-70. doi:10.1016/j. eururo.2014.01.040

8. Braga-Basaria M, Dobs AS, Muller DC, et al. Metabolic syndrome in men with prostate cancer undergoing long-term androgen-deprivation therapy. J Clin Oncol. 2006;24:3979-3983. doi:10.1200/JCO.2006.05.9741

9. Engeland A, Tretli S, Bjorge T. Height, body mass index, and prostate cancer: a follow-up of 950000 Norwegian men. $\mathrm{Br}$ $J$ Cancer. 2003;89:1237-1242. doi:10.1038/sj.bjc.6601206

10. Gong Z, Neuhouser ML, Goodman PJ, et al. Obesity, diabetes, and risk of prostate cancer: results from the prostate cancer prevention trial. Cancer Epidemiol Biomarkers Prev. 2006;15:1977-1983. doi:10.11 58/1055-9965.EPI-06-0477

11. Holmberg L. Obesity, nutrition, and prostate cancer: insights and issues. Eur Urol. 2013;63:821-822. doi:10.1016/j.eururo.2013.01.033

12. Mistry T, Digby JE, Desai KM, et al. Obesity and prostate cancer: a role for adipokines. Eur Urol. 2007;52:46-53. doi:10.1016/j. eururo.2007.03.054

13. Grossmann M, Wittert G. Androgens, diabetes and prostate cancer. Endocr Relat Cancer. 2012;19:F47-F62. doi:10.1530/ERC-12-0067

14. Bhindi B, Jiang $\mathrm{H}$, Poyet $\mathrm{C}$, et al. Creation and internal validation of a biopsy avoidance prediction tool to aid in the choice of diagnostic approach in patients with prostate cancer suspicion. Urol Oncol Semin Orig Invest. 2017;35:604.e17-604.e24. doi:10.1016/j.urolonc.2017.06.044

15. Andriole GL, Bostwick DG, Brawley OW, et al. Effect of dutasteride on the risk of prostate cancer. N Engl J Med. 2010;362:1192-1202. doi:10.1056/NEJMoa0908127

16. Fleshner NE, Lucia MS, Egerdie B, et al. Dutasteride in localised prostate cancer management: the REDEEM randomised, double-blind, placebo-controlled trial. Lancet. 2012;379:1103-1111. doi:10.1016/S0140-6736(11)61619-X

17. Bursac Z, Gauss CH, Williams DK, et al. Purposeful selection of variables in logistic regression. Source Code Biol Med. 2008;3:17. doi:10.1186/1751-0473-3-17

18. Taylor JM, Ankerst DP, Andridge RR. Validation of biomarker-based risk prediction models. Clin Cancer Res. 2008;14:5977-5983. doi:10.1158/1078-0432.CCR-07-4534

19. Hsieh FY, Bloch DA, Larsen MD. A simple method of sample size calculation for linear and logistic regression. Stat Med. 1998;17:1623-1634. doi:10.1002/(SICI)1097-0258(19980730)17:14< 1623::AID-SIM871>3.0.CO;2-S
20. Price RS, Cavazos DA, De Angel RE, et al. Obesity-related systemic factors promote an invasive phenotype in prostate cancer cells. Prostate Cancer Prostatic Dis. 2012;15:135-143. doi:10.1038/pcan.2011.54

21. Sharma J, Gray KP, Harshman LC, et al. Elevated IL-8, TNF-alpha, and MCP-1 in men with metastatic prostate cancer starting androgen-deprivation therapy (ADT) are associated with shorter time to castration-resistance and overall survival. Prostate. 2014;74:820-828. doi:10.1002/pros.22788

22. Giri D, Ozen M, Ittmann M. Interleukin-6 is an autocrine growth factor in human prostate cancer. Am J Pathol. 2001;159:2159-2165. doi:10.1016/S0002-9440(10)63067-2

23. Nakashima J, Tachibana M, Horiguchi Y, et al. Serum interleukin 6 as a prognostic factor in patients with prostate cancer. Clin Cancer Res. 2000;6:2702-2706.

24. Moore SC, Leitzmann MF, Albanes D, et al. Adipokine genes and prostate cancer risk. Int $J$ Cancer. 2009;124:869-876. doi:10.1002/ijc. v124:4

25. Lu Y, Cai Z, Galson DL, et al. Monocyte chemotactic protein-1 (MCP-1) acts as a paracrine and autocrine factor for prostate cancer growth and invasion. Prostate. 2006;66:1311-1318. doi:10.1002/(ISSN)1097-0045

26. Lu Y, Chen Q, Corey E, et al. Activation of MCP-1/CCR2 axis promotes prostate cancer growth in bone. Clin Exp Metastasis. 2009;26:161-169. doi:10.1007/s10585-008-9226-7

27. Kim HJ, Lee YS, Won EH, et al. Expression of resistin in the prostate and its stimulatory effect on prostate cancer cell proliferation. $B J U$ Int. 2011;108:E77-E83. doi:10.1111/j.1464-410X.2010.09813.X

28. Smith MR, Lee H, Fallon MA, et al. Adipocytokines, obesity, and insulin resistance during combined androgen blockade for prostate cancer. Urology. 2008;71:318-322. doi:10.1016/j.urology.2007.08.035

29. Nishimura K, Soda T, Nakazawa S, et al. Serum adiponectin and leptin levels are useful markers for prostate cancer screening after adjustments for age, obesity-related factors, and prostate volume. Minerva Urol Nefrol. 2012;64:199-208.

30. Bub JD, Miyazaki T, Iwamoto Y. Adiponectin as a growth inhibitor in prostate cancer cells. Biochem Biophys Res Commun. 2006;340:1158-1166. doi:10.1016/j.bbrc.2005.12.103

31. Burton A, Martin RM, Holly J, et al. Associations of adiponectin and leptin with stage and grade of PSA-detected prostate cancer: the ProtecT study. Cancer Causes Control. 2013;24:323-334. doi:10.1007/s10552-012-0118-4

32. Li H, Stampfer MJ, Mucci L, et al. A 25-year prospective study of plasma adiponectin and leptin concentrations and prostate cancer risk and survival. Clin Chem. 2010;56:34 43. doi:10.1373/clinchem.2009.133272

\section{Publish your work in this journal}

Cancer Management and Research is an international, peer-reviewed open access journal focusing on cancer research and the optimal use of preventative and integrated treatment interventions to achieve improved outcomes, enhanced survival and quality of life for the cancer patient.
The manuscript management system is completely online and includes a very quick and fair peer-review system, which is all easy to use. Visit http://www.dovepress.com/testimonials.php to read real quotes from published authors. 